\title{
Epidemiological and genetic characteristics of swine pseudorabies virus in mainland China between 2012 and 2017
}

\author{
Ying Sun ${ }^{1}$, Wan Liang ${ }^{1,2}$, Qingyun Liu ${ }^{1,3}$, Tingting Zhao ${ }^{1,3}$, Hechao Zhu ${ }^{1,3}$, Lin Hua ${ }^{1,3}$, Zhong Peng ${ }^{\text {Corresp.. }}$

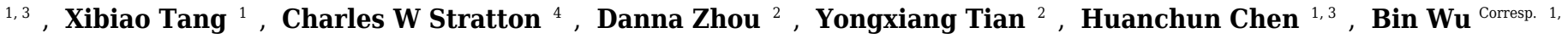 \\ ${ }^{1}$ The Cooperative Innovation Center for Sustainable Pig Production, College of Animal Science and Veterinary Medicine, Huazhong Agricultural University, \\ Wuhan, China \\ ${ }^{2}$ Key Laboratory of Prevention and Control Agents for Animal Bacteriosis (Ministry of Agriculture), Institute of Animal Husbandry and Veterinary Science, \\ Hubei Academy of Agricultural Sciences, Wuhan, China \\ 3 State Key Laboratory of Agricultural Microbiology, Huazhong Agricultural University, Wuhan, China \\ 4 Department of Pathology, Microbiology and Immunology, Vanderbilt University Medical Center, Nashville, United States \\ Corresponding Authors: Zhong Peng, Bin Wu \\ Email address: pengzhong@mail.hzau.edu.cn, wub@mail.hzau.edu.cn
}

The outbreak of pseudorabies (PR) in many Bartha-K61 vaccinated farms in China in late 2011 has seriously damaged the pig industry of one of the largest producers of pork products in the world. To understand the epidemiological characteristics of the pseudorabies virus (PRV) strains currently prevalent in China, a total of 16,256 samples collected from pig farms suspected of PRV infection in 27 Provinces of China between 2012 and 2017 were evaluated for detection of PRV. Since the extensive use of gE-deleted PRV vaccine in China, the PRV-gE was applied for determining wild-type virus infection by PCR. Of the 16,256 samples detected, approximately 1,345 samples were positive for the detection of PRV-gE, yielding an average positive rate of $8.27 \%$. The positive rates of PRV detection from 2012 to 2017 were 11.92\% (153/1284), 12.19\% (225/1846), 6.70\% (169/2523), $11.10 \%$ (269/2424), 5.57\% (147/2640), and 6.90\% (382/5539), respectively. To understand the genetic characteristics of the PRV strains currently circulating, 25 PRV strains isolated from those PRV-gE positive samples were selected for further investigation. Phylogenetic analysis based on $\mathrm{gB}, \mathrm{gC}$, and $\mathrm{gE}$ showed that PRV strains prevalent in China had a remarkably distinct evolutionary relationship with PRVs from other countries, which might explain the observation that Bartha-K61 vaccine was unable to provide full protection against emergent strains. Sequence alignments identified many amino acid changes within the $\mathrm{gB}, \mathrm{gC}$, and $\mathrm{gE}$ proteins of the PRVs circulating in China after the outbreak compared to those from other countries or those prevalent in China before the outbreak; those changes also might affect the protective efficacy of previously used vaccines in China, as well as being associated in part with the increased virulence of the current PRV epidemic strains in China. 
1 Epidemiological and genetic characteristics of swine pseudorabies virus in 2 mainland China between 2012 and 2017

3

4

5

6

\section{Running title: Epidemiological characteristics of PRV}

Ying Sun ${ }^{1 \dagger}$, Wan Liang ${ }^{1,2 \dagger}$, Qingyun Liu ${ }^{1,3}$, Tingting Zhao ${ }^{1,3}$, Hechao Zhu ${ }^{1,3}$, Lin Hua ${ }^{1,3}$, Zhong Peng ${ }^{1,3^{*}}$, Xibiao Tang ${ }^{1}$, Charles W. Stratton ${ }^{4}$, Danna Zhou ${ }^{2}$, Yongxiang Tian ${ }^{2}$, Huanchun Chen ${ }^{1,3}$, Bin $\mathrm{Wu}^{1,3^{*}}$

1 The Cooperative Innovation Center for Sustainable Pig Production, College of Animal Science and Veterinary Medicine, Huazhong Agricultural University, Wuhan, China

${ }^{2}$ Key Laboratory of Prevention and Control Agents for Animal Bacteriosis (Ministry of Agriculture), Institute of Animal Husbandry and Veterinary Science, Hubei Academy of Agricultural Sciences, Wuhan, China

${ }^{3}$ State Key Laboratory of Agricultural Microbiology, Huazhong Agricultural University, Wuhan, China

${ }^{4}$ Department of Pathology, Microbiology and Immunology, Vanderbilt University Medical Center, Nashville, Tennessee, USA

${ }^{*}$ Corresponding authors. E-mail addresses: pengzhong@mail.hzau.edu.cn (Z. Peng); wub@mail.hzau.edu.cn (B. Wu)

† These authors contributed equally to this work.

\section{ORCIDs:}

Wan Liang: 0000-0002-1612-3422

Zhong Peng: 0000-0001-5249-328X

Danna Zhou: 0000-0001-9616-2976

Bin Wu: 0000-0001-9078-386X 
The outbreak of pseudorabies (PR) in many Bartha-K61 vaccinated farms in China in late 2011 has seriously damaged the pig industry of one of the largest producers of pork products in the world. To understand the epidemiological characteristics of the pseudorabies virus (PRV) strains currently prevalent in China, a total of 16,256 samples collected from pig farms suspected of PRV infection in 27 Provinces of China between 2012 and 2017 were evaluated for detection of PRV. Since the extensive use of gEdeleted PRV vaccine in China, the PRV-gE was applied for determining wild-type virus infection by PCR. Of the 16,256 samples detected, approximately 1,345 samples were positive for the detection of PRV-gE, yielding an average positive rate of $8.27 \%$. The positive rates of PRV detection from 2012 to 2017 were $11.92 \%$ (153/1284), 12.19\% (225/1846), $6.70 \%$ (169/2523), $11.10 \%$ (269/2424), 5.57\% (147/2640), and $6.90 \%$ vaccine was unable to provide full protection against emergent strains. Sequence those prevalent in China before the outbreak; those changes also might affect the

51 protective efficacy of previously used vaccines in China, as well as being associated in 


\section{Introduction}

54 Pseudorabies virus (PRV) mainly causes reproductive failure in sows as well as

55 respiratory and neurological symptoms in piglets (Mettenleiter, 2000;Nauwynck et al., 2007). PRV possesses a double-stranded liner DNA genome which contains more than 70 functional genes encoding proteins participating in the formation of viral capsid, tegument, and envelope (Pomeranz et al., 2005). Among these proteins, the envelope component proteins $\mathrm{gB}$ and $\mathrm{gC}$ induce cellular and humoral immune responses (Ober et al., 1998;Ober et al., 2000), while gE acts as a major virulence determinant of PRV to pigs (Kimman et al., 1992;Wang et al., 2014). These three genes are commonly used for monitoring the evolution of PRV (Muller et al., 2011;Sozzi et al., 2014;Yu et al., 2014;Wang et al., 2015).

The first report of a PRV outbreak in China occurred in the 1950s. In the 1970s, an inactivated vaccine derived from PRV strain Bartha-K61 was imported from Hungary to China (Yuan et al., 1983;An et al., 2013). The widespread use of this vaccine in China was able to control outbreaks of pseudorabies between 1990 and 2011 (Tong and Chen, 1999). However, since late 2011, a pseudorabies (PR)-like disease has occurred in many Chinese pig farms that had been vaccinating pigs with the Bartha-K61 vaccine. PRV has been finally confirmed to be responsible for those outbreaks (An et al., 2013;Peng et al., 2013; Luo et al., 2014;Wang et al., 2014;Yu et al., 2014). A number of studies have noted that the Bartha-K61 vaccine appears to be unable to provide full protection against PRV strains isolated from those outbreaks (An et al., 2013;Wang et al., 2014;Yu et al., 2014).

75 These findings suggest that there may be important changes in the PRVs currently 
76 circulating in China. However, genetic information as well as epidemiological data about

77 PRV strains currently circulating in China is limited. Therefore, in this study, we report the detection/genetic analysis of PRVs recovered from pigs in China between 2012 and 2017. The aim of this study is to understand the epidemiological and genetic characteristics of PRVs that are currently prevalent in China.

\section{Materials and methods}

Samples collection and virus isolation

A total of 16,256 samples including tissue from lungs, lymph nodes, brains, serums, stillbirths, kidneys, and spleens were collected from pigs of different ages with signs suspected of PRV infection in farms (No. of sows $\geq 100$ ) in 27 Provinces in mainland China, excluding Ningxia and Tibet, between January, 2012 and December, 2016 (Figure 1). The number of samples collected in 2012, 2013, 2014, 2015, 2016 and 2017 was 1284, 1846, 2523, 2424, 2640 and 5539, respectively. After collection, tissues were minced, immersed with Dulbecco's modified Eagle medium (DMEM), and homogenized using a QIAGEN TissueLyser II (QIAGEN Germany). Sample homogenates were then frozen at $-80{ }^{\circ} \mathrm{C}$ and thawed for three times. Following centrifugation at $5000 \mathrm{rpm}$ for 5 min, the supernatants were harvested for DNA and/or virus isolation.

Template DNA for PCR detecting PRV was isolated using a Universe Genomic DNA Kit (CWBIO, Beijing, China) following the manufacturer's instructions. For virus isolation, homogenate supernatants were filtered using a $0.22 \mu \mathrm{m}$ membrane, and inoculated into 
98 PK-15 cells (Purchased from ATCC). Cells were then incubated in a $37^{\circ} \mathrm{C}$ incubator 99 supplemented with $5 \%$ CO2. Cell culture with obvious CPE was used for further 100 plaque purification assays. Briefly, PK-15 cells were plated into a 6-well plate, and a 101 series of 10 -fold dilutions (from $10^{-1}$ to $10^{-6}$ ) of virus was inoculated. The plate was 102 incubated at $37{ }^{\circ} \mathrm{C}$ under an atmosphere containing $5 \% \mathrm{CO}_{2}$ for $2 \mathrm{~h}$ and was shaken one 103 time every $15 \mathrm{~min}$. After incubation, the virus was discarded and the cells were washed 104 using DMEM for two times. Finally, DMEM medium containing $1 \%$ low melting agarose was added into each of the wells, and the plate was incubated at $4{ }^{\circ} \mathrm{C}$ until the medium 106 solidified. The plate was then moved into a $37^{\circ} \mathrm{C}$ cell incubator for plaque formation.

Plaques with suitable size were selected and inoculated into $500 \mu \mathrm{L}$ DMEM, frozen and thawed for three times, and then diluted 2-fold in DMEM for the second round of plaque purification assay. After that, plaque fluid was inoculated into PK-15 cells and 110 cultured in flask.

\section{PRV detection}

Polymerase chain reaction (PCR) assays were designed to detect the presence of PRV gE gene from the clinical samples using the DNA isolated as template as well as the primers listed in Table 1. The gE gene was used as the target gene because the $\mathrm{gE}-$ deleted pseudorabies virus (PRV) vaccine has been used in China extensively, and the detection of the gene could be applied for determining wild-type virus infection. As shown

118 in Table 1, primers gE1-F and gE1-R were designed for the detection of gE. PCR reactions were performed in a $25 \mu \mathrm{L}$ volume mixture containing $12.5 \mu \mathrm{L} 2 \times$ Taq Master mix (TAKARA, Japan), $8.5 \mu \mathrm{L}$ nucleotide-free water, each of the forward and reverse 
121 primers $1 \mu \mathrm{L}, 1 \mu \mathrm{L}$ DMSO, and $1 \mu \mathrm{L}$ template DNA. Thermocycler conditions used for

122 PCR were $95{ }^{\circ} \mathrm{C}$ for $5 \mathrm{~min}$, followed by 35 cycles of denaturation at $95{ }^{\circ} \mathrm{C}$ for $30 \mathrm{~s}$, 123 annealing at $55^{\circ} \mathrm{C}, 30 \mathrm{~s}$ for $\mathrm{gE}$, and extension at $72^{\circ} \mathrm{C}$ for $1 \mathrm{~min}$, with a final extension 124 at $72{ }^{\circ} \mathrm{C}$ for $10 \mathrm{~min}$ before storage at $4{ }^{\circ} \mathrm{C}$. The PCR product was visualized using $1 \%$ 125 agarose gel electrophoresis under ultraviolet light.

127 Sequencing and phylogenetic analysis

PCR assays were also designed for analysing the $\mathrm{gB}, \mathrm{gC}$, and $\mathrm{gE}$ genes of the PRVs currently circulating in China. The PCR volumes were the same as that used for PRV detection from the samples. Cycling conditions were $95^{\circ} \mathrm{C}$ for $5 \mathrm{~min}$, followed by 35 cycles of denaturation at $95{ }^{\circ} \mathrm{C}$ for $30 \mathrm{~s}$, annealing at $60{ }^{\circ} \mathrm{C}$ for $30 \mathrm{~s}$, and extension at $72{ }^{\circ} \mathrm{C}$ for $1 \mathrm{~min}$, with a final extension at $72{ }^{\circ} \mathrm{C}$ for $10 \mathrm{~min}$ before storage at $4{ }^{\circ} \mathrm{C}$. The PCR product was visualized using $1 \%$ agarose gel electrophoresis under ultraviolet light.

After amplification, PCR products were purified using a TIANgel Midi Purification Kit (TIANgel, China) and cloned into a pMD19-T vector (TAKARA, Japan). Plasmids carrying either $\mathrm{gB}$, gC, or $\mathrm{gE}$ were extracted and sent to Genscript (Nanjing, China) for DNA sequencing. The nucleotide sequences of $\mathrm{gB}, \mathrm{gC}$, and/or $\mathrm{gE}$ were edited and aligned (using BioEdit software) and then translated into aminoacids from each gene and then compared using DNAStar. Phylogenetic trees were generated through MEGA X, using

141 neighbor-joining algorithm with 1,000 bootstrapping. Sequences of PRV strains listed in 142 Table 2 retrieved from NCBI were used as references. 


\section{Results}

145 PCR detection of PRV in mainland China

146 Of the 16,256 samples, 1,345 samples were positive for the detection of PRV-gE, yielding

147 an average positive rate of $8.27 \%$. The positive rates of PRV detection from 2012 to 2017

148 were $11.92 \%$ (153/1284), 12.19\% (225/1846), 6.70\% (169/2523), 11.10\% (269/2424),

$1495.57 \%(147 / 2640)$, and $6.90 \%$ (382/5539), respectively. Monthly, higher positivity rates of

150 PRV were detected in January, February, March, April, June, October, November and

151 December; and winter (December, January and February), spring (March, April, and May)

152 and autumn (September, October and November) were the seasons with the high

153 positivity rate of PRV detection during 2012 and 2017 (Figure 2A and 2B).

Mainland China is divided into seven parts including Northeastern China, Northern China,

Eastern China, Central China, Southern China, Northwestern China, and Southwestern

157 China (Figure 1). Among these graphic regions, the positive rates of PRV detection in

Eastern China and Central China between 2012 and 2017 were higher than 10.00\%, while the positive rates in other parts of China between 2012 and 2017 ranged from approximately $7.00 \%$ and $10.00 \%$ (Figure 1 ). In addition, the positivity rate of PRV detection in different graphic regions between different years displayed diversity. For instance, the positive rates of PRV detection in Northern China in 2012, 2013 and 2015 were higher than $15.00 \%$, but the positivity rates in 2014 and 2016 were lower than 
165 while it was only $1.80 \%$ in 2013 , and $6.90 \%$ in $2014,5.97 \%$ in 2015 , but zero in 2016 ; in

166 Northwestern China, the positivity rate of PRV detection in 2012 and 2013 were higher

167 than $20.00 \%$, and approximately $10.40 \%$ in 2014 and 2015, but zero in 2016 (Figure 3).

$\mathrm{PRV}$ isolation

To understand the genetic characteristics of PRVs currently circulating in China, a total

171 of 25 PRV strains isolated herein were used for further analysis in this study (Table 3).

172 Most of those strains were isolated from lungs and their $\operatorname{TCID}_{50} / 0.1 \mathrm{~mL}$ values ranged 173 from $10^{6.72}$ to $10^{7.96}$.

Phylogenetic characteristics

176 Phylogenetic analysis using $\mathrm{gB}, \mathrm{gC}$, and/or $\mathrm{gE}$ sequence showed that the PRV isolates

177 from China were located on a phylogenetic branch, which was distinct from the those

178 isolates from other countries of the world (Figures 4A, B, C). According to previous

179 study (Ye et al., 2015), those isolates from China belonged to genotype II, while those 180 isolates from the other parts of the world including Bartha, Becker, Kaplan, and NIA3 181 were genotype I strains. Interestingly, one isolate from China in 2016, which we 182 designed $\mathrm{HuB}$, should be determined as a genotype II strain (Figure 4B) according to 183 Ye's study, in which PRVs were phylogenetically divided into 2 major genotypes, 184 genotype I and genotype II, based on the analysis of gC gene (Ye et al., 2015). 185 However, this isolate had a closer relationship to the genotype I strains when using $\mathrm{gB}$ 186 to perform the phylogenetic analysis (Figure 4A). 
188

189

190

191

192

193

194

195

196

197

198

199

200

201

202

203

204

205

206

207

Analysis of $\mathrm{gB}, \mathrm{gC}$ and $\mathrm{gE}$

The maximal amino acid sequence divergence for $\mathrm{gB}, \mathrm{gC}$, and $\mathrm{gE}$ proteins of the $25 \mathrm{PRV}$ isolates were $5.2,2.7$, and $2.6 \%$ within the isolates, and were $8.4,9.2$, and $5.5 \%$ compared to those isolates from the other countries, respectively. The maximal amino acid sequence divergence for the three proteins of the 25 isolates were $4.8,9.9$, and $2.8 \%$ compared to those strains prevalent in China before 2012, and were 4.8, 2.7, and 2.8\% after 2012.

Alignment of amino acid sequences of $\mathrm{gB}$ found the isolates from China mainly had three types of mutations within the protein compared those strains from the other countries. The isolates from China harbored an-amino acid insertion at site $94(G)$, a substitution of ten amino acids at sites $53(A \rightarrow T), 55(P \rightarrow T), 70(T \rightarrow A), 81(N \rightarrow D), 82(D \rightarrow G), 83$ $(\mathrm{V} \rightarrow \mathrm{F}), 87(\mathrm{~A} \rightarrow \mathrm{E}), 93(\mathrm{E} \rightarrow \mathrm{D}), 96(\mathrm{~F} \rightarrow \mathrm{V})$ and $102(\mathrm{E} \rightarrow \mathrm{D})$, and a deletion of three-amino acids at sites 75-77 (S, P and G) compared to Bartha-Hungary, Kaplan-Hungary and NIA3-Japan. In addition, there were also some different substitutions at different sites within the gB protein of the 25 isolates compared to Bartha-Hungary. For example, HuBHZChina-2016 harbored a substitution of one amino acid at sites $11(P \rightarrow A)$ and $12(R \rightarrow G)$, while strains JSZL-China-2016, HuB-China-2016, and SDRZ-China-2016 had an amino acid substitution at sites $12(R \rightarrow H), 67(A \rightarrow V)$, and $228(K \rightarrow E)$, respectively (Figure 5). 
208 For the $\mathrm{gC}$ protein, the isolates from China had an insertion of seven amino acids at sites

209 63-69 (A, A, A, S, T, P and A) within the protein compared to the genotype I strains; while

210 strain LXB6-China-2009 harbored an insertion of six amino acids at sites 64-69 (A, A, S,

211 T, P and A). In particular, those isolates from China after 2012 contained a substitution of 212 twenty-three amino acids substitutions at sites $14(P \rightarrow L), 16(A \rightarrow T), 52(P \rightarrow S), 55$ $213(A \rightarrow E), 57(A \rightarrow V), 59(P \rightarrow G), 60(E \rightarrow T), 76(A \rightarrow V), 87(P \rightarrow Q), 90(N \rightarrow G), 102(A \rightarrow S)$,

$214130(\mathrm{~F} \rightarrow \mathrm{V}), 163(\mathrm{~S} \rightarrow \mathrm{P}), 186(\mathrm{~T} \rightarrow \mathrm{A}), 188(\mathrm{~V} \rightarrow \mathrm{A}), 190(\mathrm{E} \rightarrow \mathrm{V}), 191(\mathrm{D} \rightarrow \mathrm{V}), 243(\mathrm{~S} \rightarrow \mathrm{H})$, $215431(\mathrm{~L} \rightarrow \mathrm{M}), 449(\mathrm{~A} \rightarrow \mathrm{T}), 457(\mathrm{~S} \rightarrow \mathrm{T}), 461(\mathrm{~V} \rightarrow \mathrm{T})$ and $467(\mathrm{G} \rightarrow \mathrm{A})$ compared to the 216 genotype I strains (Figure 6). In addition, some other substitutions were also found during 217 the analysis: HuN-China-2016, SDRZ-China-2016, HuB-China-2016, HuN-China-2016, 218 HuBAL-China-2016, and SDRZ-China-2016 harbored amino acid substitutions at sites $219106(\mathrm{~K} \rightarrow \mathrm{T}), 107(\mathrm{R} \rightarrow \mathrm{C})$, 210/227 $(\mathrm{A} \rightarrow \mathrm{T}), 235(\mathrm{~A} \rightarrow \mathrm{V}), 300(\mathrm{~L} \rightarrow \mathrm{P})$ and $386(\mathrm{~W} \rightarrow \mathrm{R})$, 220 respectively.

222 The sequence alignments of the $\mathrm{gE}$ protein found also found some amino acid mutations 223 within the protein of the genotype II strains compared to the genotype I isolates. 224 Compared with Kaplan-Hungary and NIA3-Japan, the 25 isolates contained an insertion 225 of one amino acid (D) at site 48 (Figure 7). Compared with Min-A-China-2002, the 25 226 isolates contained a deletion of one amino acid (D) at site 493. In particular, HeNJYG227 China-2016, HuBWX-China-2016, HeNXY-China-2016 and GDHDYC-China-2016 228 deleted an amino acid (D) at site 491, while HuN-China-2016 and SDRZ-China-2016 had 229 a deletion of one amino acid at sites 489 (Y) and 495 (D) compared to Min-A-China-2002, 230 respectively; strain HuB-China-2016 deleted four amino acids (DLNG) at sites 61-64 
231 compared to Min-A-China-2002. In addition to amino acid deletion, sequence alignments

232 also identified amino acid substitutions within the $\mathrm{gE}$ protein of the strains isolated herein.

233 For example, strains HeNJYG-China-2016, HuBHZ-China-2016, HuBLLP-China-2016,

234 HuN-China-2016, HuN-China-2016, and SX-China-2016 contained one amino acid 235 substitution at sites $336(\mathrm{D} \rightarrow \mathrm{G}), 2(R \rightarrow G), 473(\mathrm{~T} \rightarrow \mathrm{M}), 49(\mathrm{~L} \rightarrow R), 573(A \rightarrow T)$, and 526

$236(D \rightarrow G)$ compared to the genotype I strains, respectively. Particularly, one strain, SDRZ-

237 China-2016, contained four substitutions at sites $407(V \rightarrow L), 487(E \rightarrow D), 499(E \rightarrow D)$ and $238535(\mathrm{E} \rightarrow \mathrm{D})$ compared to the genotype I strains.

Discussion

PRV is a common threat to the pig industry worldwide and is particularly important in China. The outbreak of PR in China in late 2011 has seriously damaged the pig industry of one of the largest producers of pork products in the world (An et al., 2013; Yu et al., 2014). The present study reported the prevalence of PRV in China between 2012 and 2017. This report is the first large-scale etiological investigation of PRV involved in most regions of China following the outbreak. The data revealed an average positive rate of detection in different regions in China (Figure 1). While there is a lack of similar data from the other studies, a nationwide surveillance detecting the PRV-gE antibody revealed that the positive rate of PRV-gE antibody in China during 2013-2016 was higher than $13.74 \%$

251 (Liu et al., 2018). These findings confirm that the prevalence of PRV remains a problem 252 in China. 
254 From the 1990 s until late $2011,>80 \%$ of pigs in China were vaccinated with the Bartha-

255 K61 vaccine, and pseudorabies was well controlled (Yu et al., 2014). This could be

256 reflected by the unpublished data from Huazhong Agricultural University Diagnostic

257 Center for Animal Infectious Diseases (Wuhan China) which indicated that the detective

258 rate of PRV in mainland China between 2010 and 2011 was lower than $6 \%$. However, the

259 positive rate of PRV increased to approximately $12 \%$ between 2012 and 2013 as revealed

260 by this study. These findings suggest that receiving the Bartha-K61 vaccine is likely to be

261 unable to provide full protection against the PRVs circulating in China after 2011. Actually,

262 this suggestion has been confirmed in laboratory (An et al., 2013;Yu et al., 2014). The

263 results from this study showed that the positive rate of PRV detection had a significant

264 decreasing after 2013, this might be because several vaccines based on the epidemic

265 strains have been developed after the 2011 outbreak, and the use of these vaccines helps

266 to decrease the infection of the virus (Wang et al., 2014; Hu et al., 2015).

268 It has been reported that PRV isolates are generally divided into two genotypes according 269 to the gC gene; PRV strains prevalent in China belong to genotype II while PRV isolates

270 from the other countries belong to genotype I (Ye et al., 2015). In agreement with this

271 report, the isolates analyzed in this study were divided into two distinct clusters according

272 to their gC genes, with the previously reported genotype I strains Bartha, Backer, Kaplan

273 and NIA3 forming one cluster and the Chinese strains including the reported genotype II

274 strains TJ, JS, and HeN1 forming the second cluster (Figure 4B). Interestingly, similar

275 results were also obtained when using gB and gE to perform the phylogenetic analysis

276 (Figures 4A and C). Those findings again confirm that PRV strains circulating in China 
277 harbor different genotypes from those spreading in the other countries. This observation

278 also might be the reason that the Bartha-K61 vaccine was unable to provide full protection

279 against these emergent strains. Interestingly, one isolate, HuB-China-2016, belonged to

280 genotype II according to $\mathrm{gC}$ and $\mathrm{gE}$, but was identified as a genotype I strain when using

$281 \mathrm{gB}$ as a phylogenetic criterion (Figure 4). These findings suggest that a genetic

282 recombination might have occurred within the genome of this isolate. In the next step of

283 this investigation, we intend to do a follow up study in which the whole genome will be

284 sequenced in order to clarify what happened with this strain.

286 The gB protein is the most conserved glycoprotein in herpesviruses and allows PRV 287 strains to enter the target cells, thus contributing directly to cell-to-cell spread 288 (Mettenleiter, 2003). In addition, this gB protein is the principle immunogen of the virus, 289 stimulating the host to produce both complement-dependent and non-complement 290 dependent neutralizing antibodies (Okazaki, 2007). Alignments of the gB protein indicated 291 that the Chinese strains had amino acid insertions, deletions, and substitutions in 292 comparison with strain Bartha-k61 (Figure 5). These amino acid changes might lead to 293 the alteration of the neutralizing epitope of the gB protein and thus alter the protective 294 efficacy of previously used Bartha-k61vaccines in China.

296 The gC protein is another important neutralizing antigen and is the major virulent protein 297 of PRV, guiding the adsorption process between the virus and target cells (Karger et al., 298 1998). Sequence alignments of the gC protein found that the most Chinese strains 
299 contained a continuous insertion of seven amino acids (AAASTPA at sites 63-69) and

300 two-amino acid substitution within the protein compared to Bartha-k61 (Figure 6). These

301 changes might influence the structure of the $\mathrm{gC}$ glycoprotein of those strains, and

302 therefore influence the virus adhesion to host cells. The gE protein is another major

303 virulent protein of PRV (Wang et al., 2015). It has been reported that only a few amino

304 acids changes are required to alter the virulence of PRV isolates (Mettenleiter et al.,

305 1994). In this study, we found that the 25 PRV strains contained amino acid-

306 insertion/deletion within the $\mathrm{gE}$ protein either compared to the isolates from other

307 countries (Kaplan-Hungary and NIA3-Japan) or compared to the isolates from China

308 before 2012 (strain Min-A-China-2002); those changes might also have an effect on the

309 virulence of PRV isolates currently circulating in China.

Conclusion

312 In summary, this study reported a large-scale etiological investigation of PRV involved in most regions of China after the outbreak of PR in late 2011. Our data revealed an average

314 positive rate of $8.27 \%$ for PRV detection between 2012 and 2017, indicating the risk of pseudorabies prevalence in China. Phylogenetic analysis showed that the evolutionary

316 relationship between the PRV isolates circulating in China and those from the other

317 countries was remarkably distinct, suggesting that vaccination with foreign strains might

318 be unable to provide full protection against currently epidemic isolates in China. In

319 addition, PRV isolates currently circulating contained different types of mutations within

320 their $\mathrm{gB}, \mathrm{gC}$, and $\mathrm{gE}$ proteins compared to those from other countries and/or those from

321 China before the outbreak; these changes also might be associated with virulence 
322

323

324

325

326

327

328

329

330

331

332

333

334

335

336

337

338

339

340

341

342

343

344

345

346

347

348

349

350

351

352

353

354

355

356

357

358

359

360

361

362

changes of the virus. In the next step, we intend to evaluate the influence of those changes on the virulence/pathogenicity of the isolates.

\section{Reference}

An, T.Q., Peng, J.M., Tian, Z.J., Zhao, H.Y., Li, N., Liu, Y.M., Chen, J.Z., Leng, C.L., Sun, Y., Chang, D., and Tong, G.Z. (2013). Pseudorabies virus variant in Bartha-K61-vaccinated pigs, China, 2012. Emerg Infect Dis 19, 1749-1755.

Hu, R.M., Zhou, Q., Song, W.B., Sun, E.C., Zhang, M.M., He, Q.G., Chen, H.C., Wu, B., and Liu, Z.F. (2015). Novel pseudorabies virus variant with defects in TK, gE and gl protects growing pigs against lethal challenge. Vaccine 33, 5733-5740.

Karger, A., Schmidt, J., and Mettenleiter, T.C. (1998). Infectivity of a pseudorabies virus mutant lacking attachment glycoproteins $C$ and D. J Virol 72, 7341-7348.

Kimman, T.G., De Wind, N., Oei-Lie, N., Pol, J.M., Berns, A.J., and Gielkens, A.L. (1992). Contribution of single genes within the unique short region of Aujeszky's disease virus (suid herpesvirus type 1) to virulence, pathogenesis and immunogenicity. J Gen Virol 73 ( Pt 2), 243-251.

Liu, Y., Zhang, S., Xu, Q., Wu, J., Zhai, X., Li, S., Wang, J., Ni, J., Yuan, L., Song, X., Zhao, B., Zhou, Z., Wang, C., and Yang, L. (2018). Investigation on pseudorabies prevalence in Chinese swine breeding farms in 2013-2016. Trop Anim Health Prod.

Luo, Y., Li, N., Cong, X., Wang, C.H., Du, M., Li, L., Zhao, B., Yuan, J., Liu, D.D., Li, S., Li, Y., Sun, Y., and Qiu, H.J. (2014). Pathogenicity and genomic characterization of a pseudorabies virus variant isolated from Bartha-K61-vaccinated swine population in China. Vet Microbiol 174, 107-115.

Mettenleiter, T.C. (2000). Aujeszky's disease (pseudorabies) virus: the virus and molecular pathogenesis-state of the art, June 1999. Vet Res 31, 99-115.

Mettenleiter, T.C. (2003). Pathogenesis of neurotropic herpesviruses: role of viral glycoproteins in neuroinvasion and transneuronal spread. Virus Res 92, 197-206.

Mettenleiter, T.C., Klupp, B.G., Weiland, F., and Visser, N. (1994). Characterization of a quadruple glycoprotein-deleted pseudorabies virus mutant for use as a biologically safe live virus vaccine. $J$ Gen Virol 75 ( Pt 7), 1723-1733.

Muller, T., Hahn, E.C., Tottewitz, F., Kramer, M., Klupp, B.G., Mettenleiter, T.C., and Freuling, C. (2011). Pseudorabies virus in wild swine: a global perspective. Arch Virol 156, 1691-1705.

Nauwynck, H., Glorieux, S., Favoreel, H., and Pensaert, M. (2007). Cell biological and molecular characteristics of pseudorabies virus infections in cell cultures and in pigs with emphasis on the respiratory tract. Vet Res 38, 229-241.

Ober, B.T., Summerfield, A., Mattlinger, C., Wiesmuller, K.H., Jung, G., Pfaff, E., Saalmuller, A., and Rziha, H.J. (1998). Vaccine-induced, pseudorabies virus-specific, extrathymic CD4+CD8+ memory Thelper cells in swine. $J$ Virol 72, 4866-4873.

Ober, B.T., Teufel, B., Wiesmuller, K.H., Jung, G., Pfaff, E., Saalmuller, A., and Rziha, H.J. (2000). The porcine humoral immune response against pseudorabies virus specifically targets attachment sites on glycoprotein gC. J Virol 74, 1752-1760.

Okazaki, K. (2007). Proteolytic cleavage of glycoprotein B is dispensable for in vitro replication, but required for syncytium formation of pseudorabies virus. J Gen Virol 88, 1859-1865. 
Peng, J., An, T., Zhao, H., Liu, Y., Chen, J., Leng, C., Sun, Y., Chang, D., Tian, Z., and Tong, G. (2013). Identification and antigenic variation of new epidemiology of pseudorabies virus from swine. Chin. J. Prev. Vet. Med. 35, 1-4.

Pomeranz, L.E., Reynolds, A.E., and Hengartner, C.J. (2005). Molecular biology of pseudorabies virus: impact on neurovirology and veterinary medicine. Microbiol Mol Biol Rev 69, 462-500.

Sozzi, E., Moreno, A., Lelli, D., Cinotti, S., Alborali, G.L., Nigrelli, A., Luppi, A., Bresaola, M., Catella, A., and Cordioli, P. (2014). Genomic characterization of pseudorabies virus strains isolated in Italy. Transbound Emerg Dis 61, 334-340.

Tong, G., and Chen, H. (1999). Pseudorabies epidemic status and control measures in China. Chin. J. Vet. Sci. 19, 1-2.

Wang, C.H., Yuan, J., Qin, H.Y., Luo, Y., Cong, X., Li, Y., Chen, J., Li, S., Sun, Y., and Qiu, H.J. (2014). A novel gE-deleted pseudorabies virus (PRV) provides rapid and complete protection from lethal challenge with the PRV variant emerging in Bartha-K61-vaccinated swine population in China. Vaccine 32, 3379-3385.

Wang, Y., Qiao, S., Li, X., Xie, W., Guo, J., Li, Q., Liu, X., Hou, J., Xu, Y., Wang, L., Guo, C., and Zhang, G. (2015). Molecular epidemiology of outbreak-associated pseudorabies virus (PRV) strains in central China. Virus Genes 50, 401-409.

Ye, C., Zhang, Q.Z., Tian, Z.J., Zheng, H., Zhao, K., Liu, F., Guo, J.C., Tong, W., Jiang, C.G., Wang, S.J., Shi, M., Chang, X.B., Jiang, Y.F., Peng, J.M., Zhou, Y.J., Tang, Y.D., Sun, M.X., Cai, X.H., An, T.Q., and Tong, G.Z. (2015). Genomic characterization of emergent pseudorabies virus in China reveals marked sequence divergence: Evidence for the existence of two major genotypes. Virology 483, 32-43.

Yu, X., Zhou, Z., Hu, D., Zhang, Q., Han, T., Li, X., Gu, X., Yuan, L., Zhang, S., Wang, B., Qu, P., Liu, J., Zhai, X., and Tian, K. (2014). Pathogenic pseudorabies virus, China, 2012. Emerg Infect Dis 20, 102-104.

Yuan, Q., Wu, Y., Li, Y., Li, Z., and Nan, X. (1983). The pseudorabies vaccination research. I: pseudorabies attenuated vaccine research. Chin. J. Prev. Vet. Med. 1, 1-6. 
395 Figure legends

396 Figure 1 Samples collection from mainland China for PRV detection between 2012

397 and 2017

398

399

Figure 2 Positivity rate of PRV detection in different months (A) and seasons (B).

400

401

Figure 3 Positivity rate of PRV detection in different graphic parts of China.

402

Figure 4 Evolutionary relationships of PRV isolates based on $\mathrm{gB}(\mathrm{A}), \mathrm{gC}(\mathrm{B})$ and

404 gE (C). The evolutionary history was inferred using the Neighbor-Joining method [1].

405

The optimal tree with the sum of branch length $=0.08532423(\mathrm{gB}) / 0.11049107(\mathrm{gC}) /$

406

$0.08878838(\mathrm{gE})$ is shown. The percentage of replicate trees in which the associated

407

taxa clustered together in the bootstrap test (1000 replicates) are shown next to the

408

branches. The tree is drawn to scale, with branch lengths in the same units as those of

409

the evolutionary distances used to infer the phylogenetic tree. The evolutionary

410 distances were computed using the p-distance method and are in the units of the

411 number of amino acid differences per site. The analysis involved 50/34/33 amino acid

412 sequences. All positions containing gaps and missing data were eliminated. There were a total of $293 / 462 / 570$ positions in the final dataset. Evolutionary analyses were 414 conducted in MEGA X. 
416 Figure 5 Alignment of partial amino acid sequences of PRV gB protein. The

417 substitution regions are shown by the green boxes. The deletion region is shown by the 418 red box. The insertion region is shown by the blue box.

420 Figure 6 Alignment of complete amino acid sequences of PRV gC protein. The

421 substitution regions are shown by the green boxes. The insertion region is shown by the 422 blue box.

424 Figure 7 Alignment of complete amino acid sequences of PRV gE protein. The

425 substitution regions are shown by the green boxes. The insertion region is shown by the 426 blue box. The deletion regions are shown by the red boxes. 


\section{Figure 1}

Samples collection from mainland China for PRV detection between 2012 and 2017.

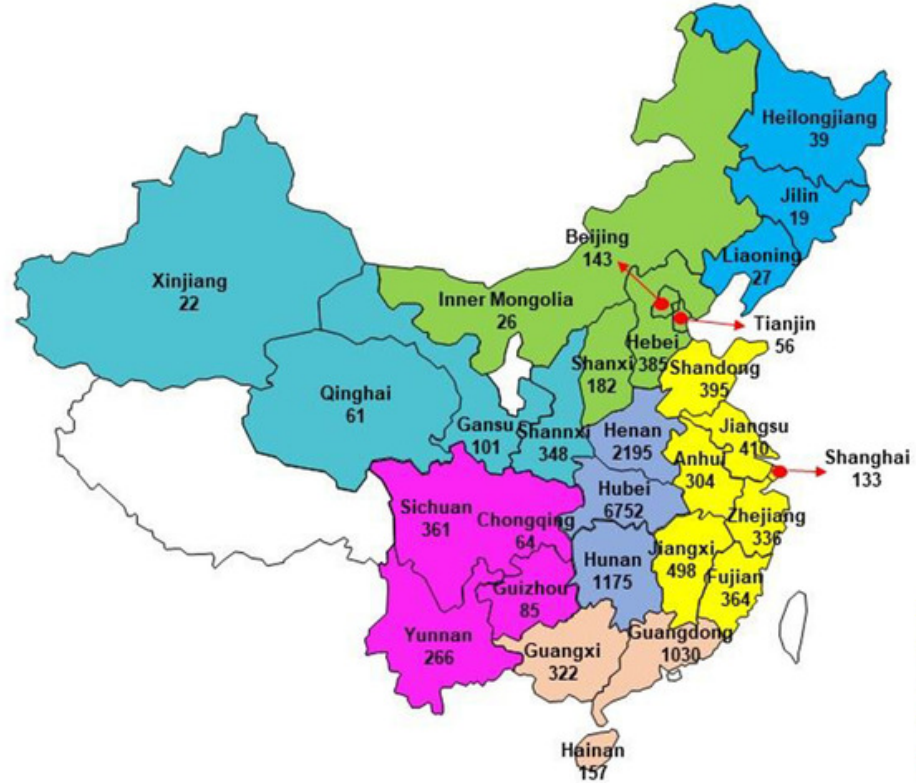

\begin{tabular}{|c|c|}
\hline Graphic regions & PRV positive rate \\
\hline Eastern China & $11.60 \%$ \\
\hline Central China & $10.90 \%$ \\
\hline Southern China & $8.59 \%$ \\
\hline Southwestern China & $8.27 \%$ \\
\hline Northeastern China & $8.24 \%$ \\
\hline Northern China & $7.16 \%$ \\
\hline Northwestern China & $6.97 \%$ \\
\hline
\end{tabular}


Figure 2

Positivity rate of PRV detection in different months (A) and seasons (B).

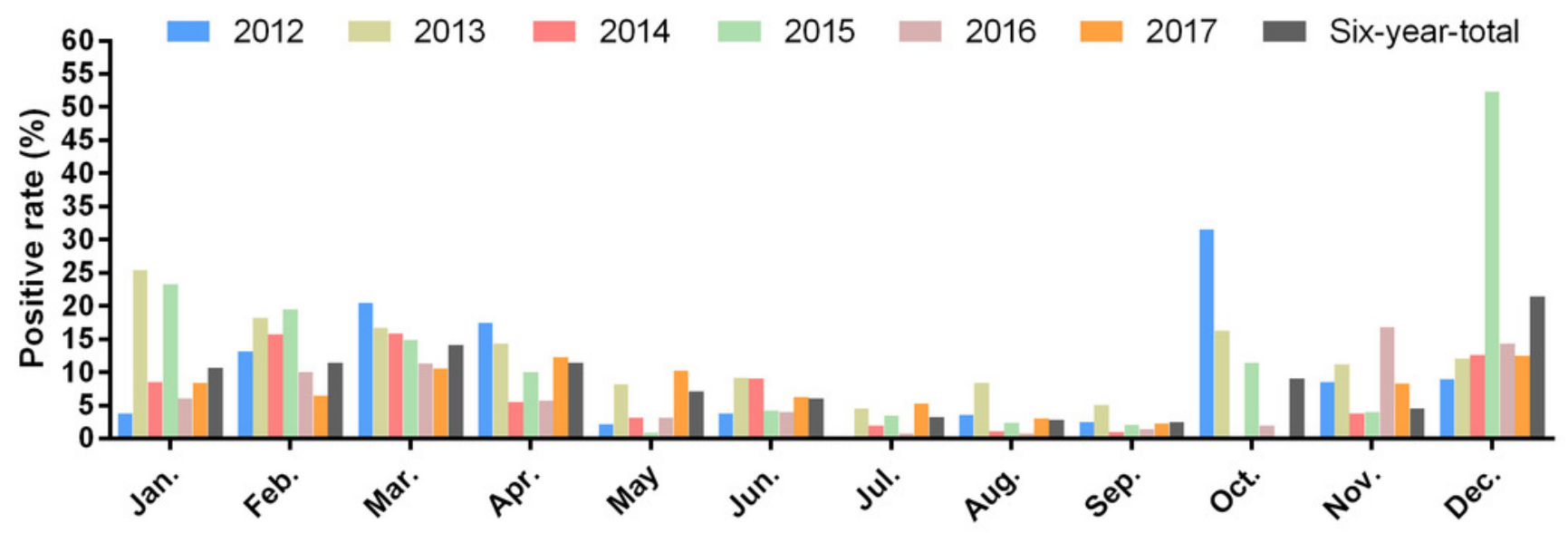

A.

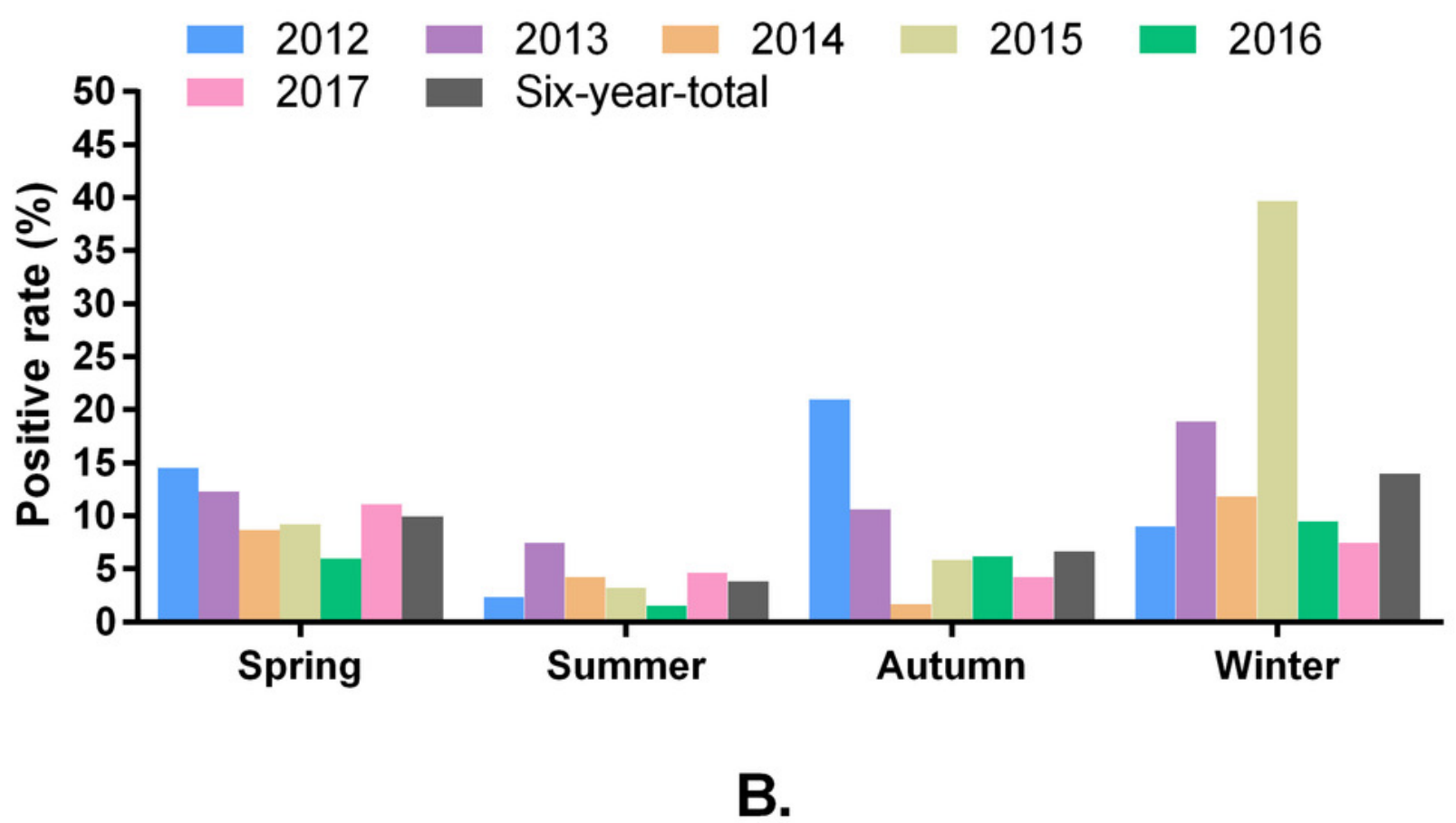


Figure 3

Positivity rate of PRV detection in different graphic parts of China.

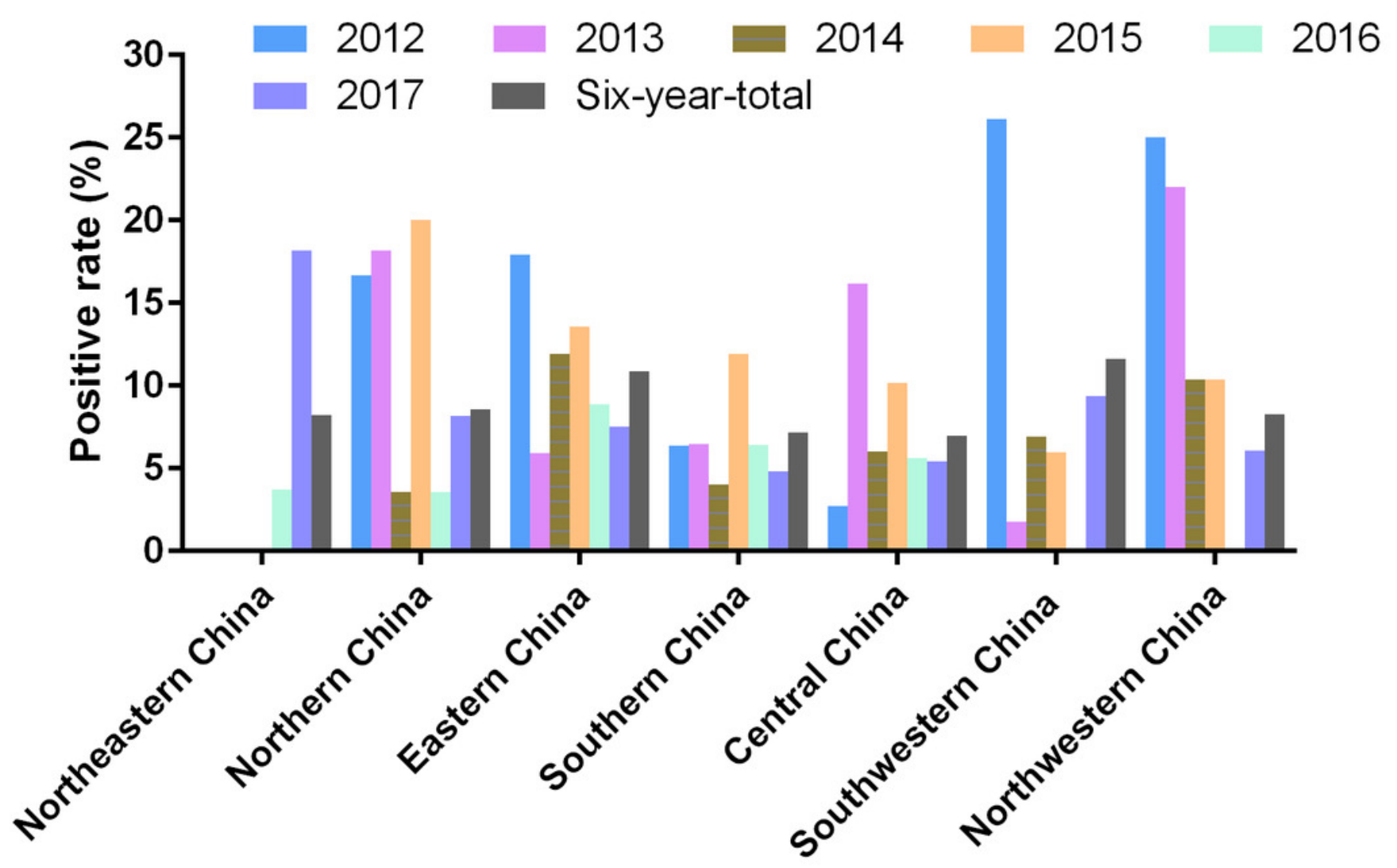




\section{Figure 4}

Evolutionary relationships of PRV isolates based on $g B(A), g C(B)$ and $g E(C)$.

The evolutionary history was inferred using the Neighbor-Joining method [1]. The optimal tree with the sum of branch length $=0.08532423(\mathrm{gB}) / 0.11049107(\mathrm{gC}) / 0.08878838(\mathrm{gE})$ is shown. The percentage of replicate trees in which the associated taxa clustered together in the bootstrap test (1000 replicates) are shown next to the branches. The tree is drawn to scale, with branch lengths in the same units as those of the evolutionary distances used to infer the phylogenetic tree. The evolutionary distances were computed using the $p$-distance method and are in the units of the number of amino acid differences per site. The analysis involved 50/34/33 amino acid sequences. All positions containing gaps and missing data were eliminated. There were a total of 293/462/570 positions in the final dataset.

Evolutionary analyses were conducted in MEGA X.

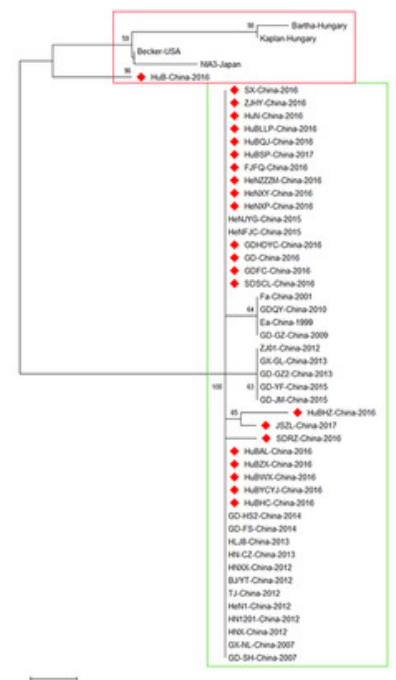

A.

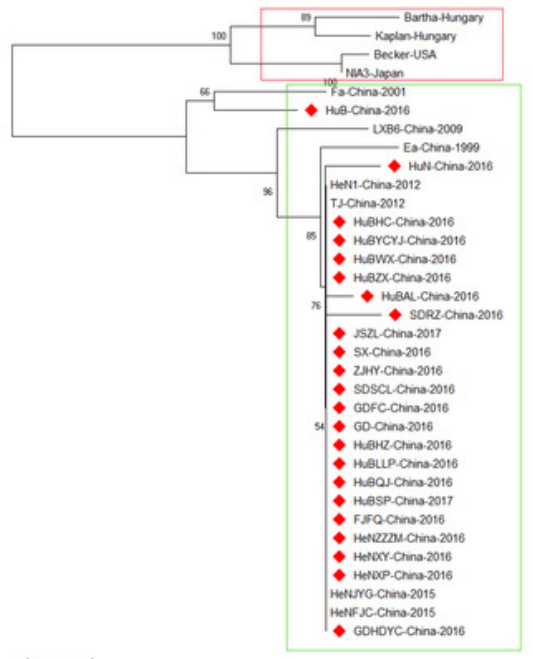

B.

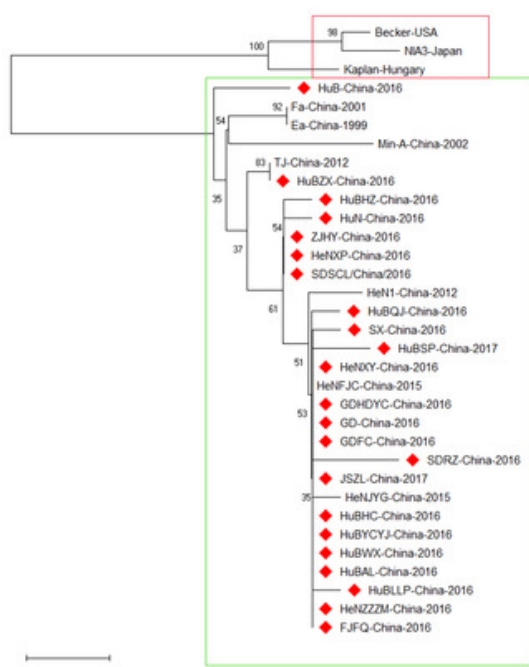

C. 
Figure 5

Alignment of partial amino acid sequences of PRV gB protein.

The substitution regions are shown by the green boxes. The deletion region is shown by the red box. The insertion region is shown by the blue box.

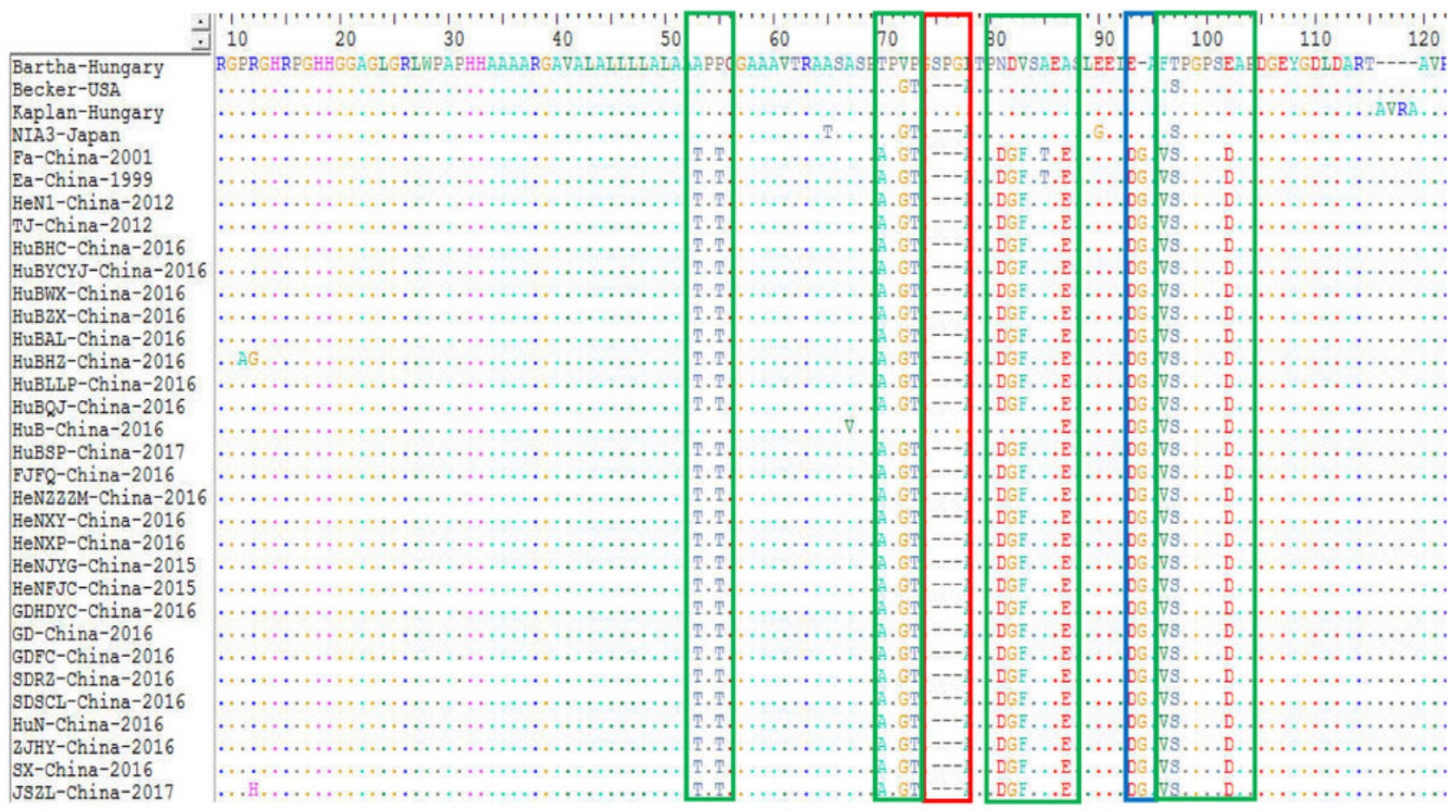




\section{Figure 6}

Alignment of complete amino acid sequences of PRV gC protein.

The substitution regions are shown by the green boxes. The insertion region is shown by the blue box. 
A.

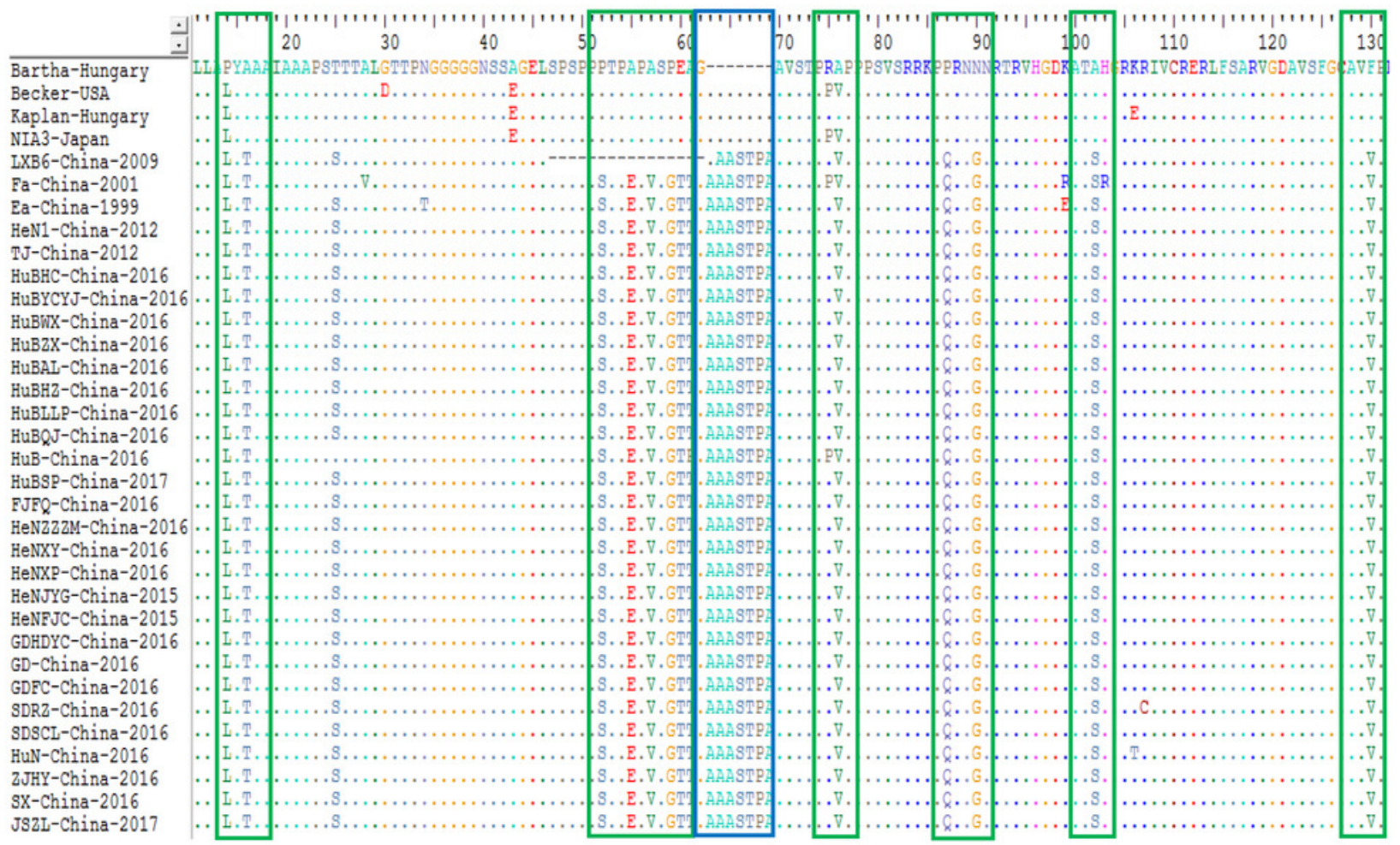

B.

\begin{tabular}{|c|c|c|c|c|c|c|c|}
\hline & 140 & 60 & 170 & 190 & 200 & 240 & 460 \\
\hline Bartha-Hungary & REYRRGRIRSPDADPEYFD & PPRS & ELPRERLLFSSANASLA: & DALTPVVEDEG & RATVANVSGEVSVRVAAADAETEGVYTWRVLSANGTEVRSANV & LLLYSg & 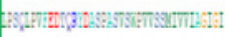 \\
\hline Becker-USA & (n.............. & ... & & .....-.Vv.. & 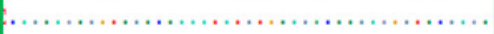 & & \\
\hline Raplan-Hungary & & & & ........... & & & \\
\hline NIA3-Japan & n............ & & & ...A. - .VV. & & & \\
\hline LXB6-China-2009 & c................ & ... & & ...ASA.VV.. & n............... & . . .н. н. & (an............... \\
\hline Fa-China-2001 & & & & ...ASA.VV.. & R. & . . ...н. & ..................... \\
\hline Ea-China-1999 & ... & ... & & ...ASA.VV.. & .................... & . . . H. & (1)............ \\
\hline HeN1-China-2012 & c........ & & & ...ASA.VV.. & & . . ... В. & .n............... \\
\hline TJ-China-2012 & c............. & $\ldots$ & & ...ASA.VV.. & (n) & . . . H. & \\
\hline HuBHC-China-2016 & c.................. & ... & & ...ASA.VV.. & (n., & . . .... & (2)........... \\
\hline-2016 & $6 . . c \ldots \ldots \ldots . . . .6$ & ... & & ...ASA.VV.. & (n) & .7..н., & ................ \\
\hline HuBWX-China-2016 & ..c............. & $\ldots$ & & ...ASA.VV.. & $\ldots \ldots \ldots \ldots \ldots \ldots \ldots \ldots \ldots \ldots$ & . . .н. & a................ \\
\hline 16 & ..c............. & ... & & ...ASA.VV.. & 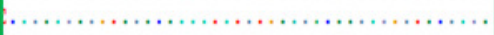 & .7..н. & a….......... \\
\hline HuBAL-C: & .c............ & $\ldots$ & & ...ASA.VV.. & (1) & . . . н. & . R............. \\
\hline HuBHz-Chin & .c. & & & ...ASA.VV.. & & . . . H. & ................... \\
\hline HuBLI & .......... & & & ...ASA.Vv.. & & . ....н. & . a.............. \\
\hline HuBQJ-China-2016 & c.............. & $\ldots$ & & ...ASA.VV.. & & . . ... н. & A $\ldots \ldots \ldots \ldots$ \\
\hline Hu. & & $\ldots$ & & WA.A.VV.. & $\ldots \ldots \ldots \ldots+\ldots \ldots \ldots \ldots \ldots, \ldots$ & . . .... & a............. \\
\hline 2017 & .c............ & $\ldots$ & & ...ASA.VV.. & ........ & . . ..н. & an............... \\
\hline FJPQ & .c.. & wh & & ...ASA.VV.. & & . . ...н. & a................ \\
\hline China-2016 & 6...c.. & . & & ...ASA.VV.. & (5) & .7..н. & a $\ldots \ldots$ \\
\hline HeNXY-China-2016 & ..c........... & $\ldots$ & & ...ASA.VV.. & 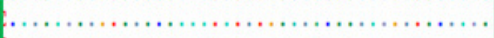 & . ...н. & A.............. \\
\hline HeNX & & & & ...ASA.VV.. & .... & . . ..н. & A............ \\
\hline HeNJYG-China-2015 & - & ... & & ...ASA.VV.. & & .7..н. & $\ldots \ldots \ldots \ldots$ \\
\hline-2015 & .c. & whe & & ...ASA.VV.. & & . . . H. H. & $\ldots \ldots \ldots \ldots$ \\
\hline GDHDYC & n....... & $\ldots$ & & ...ASA.vv.. & 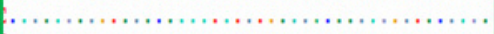 & . ...н. & A $\ldots \ldots \ldots \ldots \ldots$ \\
\hline GD-China-2016 & c.............. & L...: & & ...ASA.VV.. & & . . ..H. & $\ldots \ldots \ldots$ \\
\hline na-2016 & c. & & & ...ASA.Vv.. & . & . ...н. & A $\ldots \ldots \ldots \ldots \ldots$ \\
\hline SDR2-China-2016 & .c............. & : & & ...ASA.VV.. & & . . ... H. & A............. \\
\hline SDSCL-China-2016 & ..c... & $\ldots$ & & ...ASA.VV.. & & . ...H. & $\ldots \ldots \ldots \ldots \ldots$ \\
\hline HuN-Chin & .c........... & & & ...ASA.VV.. & 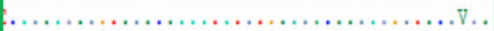 & . X..H. & 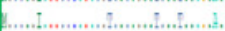 \\
\hline ZJHY-China-2016 & $c_{-}$ & $\ldots$ & & ...ASA.VV.. & & .. ... & $\ldots \ldots \ldots \ldots$ \\
\hline$s x-c$ & ..... & ... & & ‥ASA.VV.. & & . . . н. & ................. \\
\hline JSzL-China-2017 & & & & ..ASA.VV... & & . . ..H. & A............ \\
\hline
\end{tabular}




\section{Figure 7}

Alignment of complete amino acid sequences of PRV gE protein.

The substitution regions are shown by the green boxes. The insertion region is shown by the blue box. The deletion regions are shown by the red boxes. 
A.

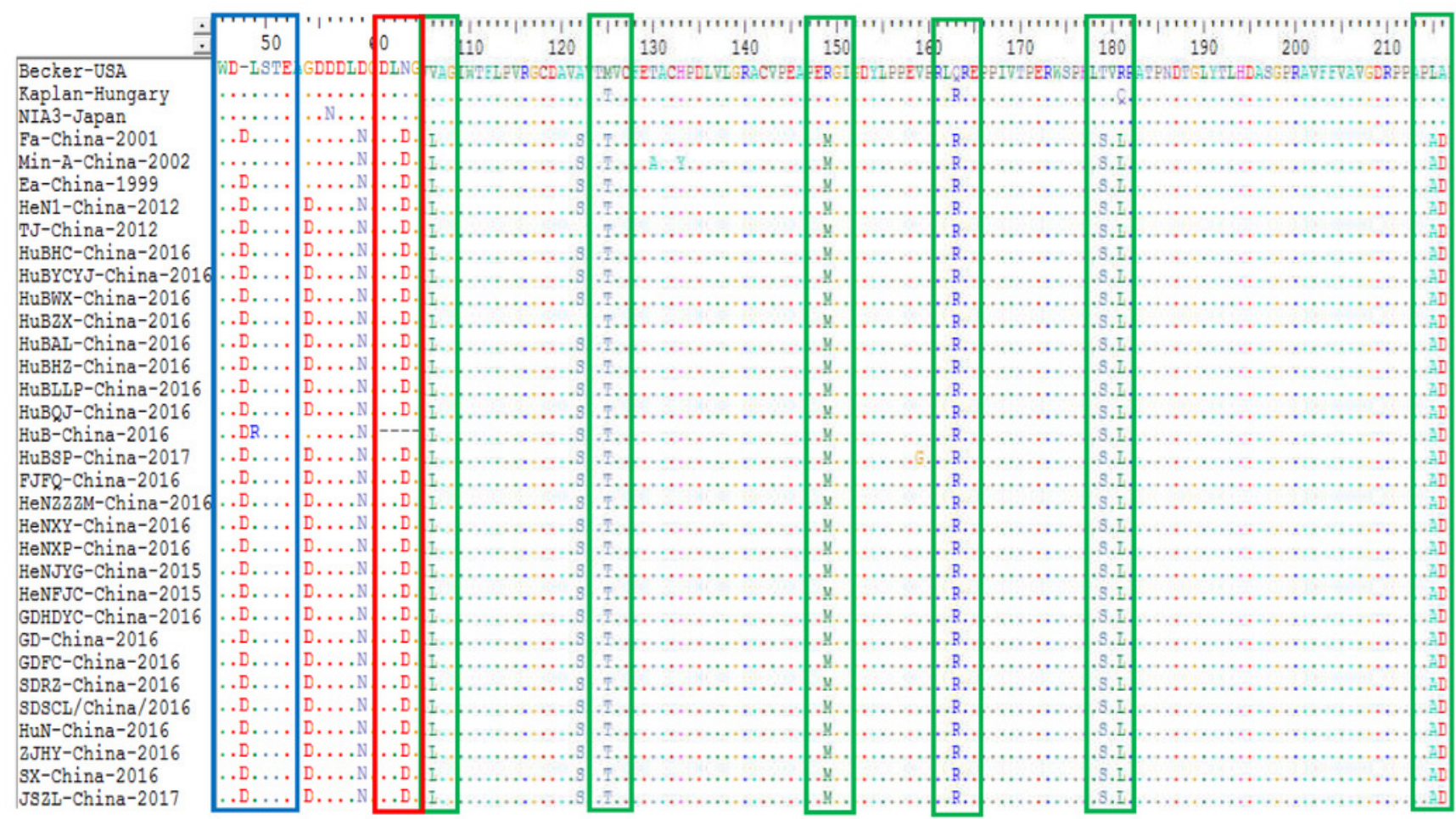

B.

\begin{tabular}{|c|c|c|c|c|c|c|c|c|c|c|}
\hline$\dot{-}$ & 460 & & 480 & & 510 & 52 & & 550 & & $580^{\circ}$ \\
\hline Becker-USA & CVLCSRRRAASRPERVPIR & GIRS & SETYTSLPT & EDYYDG--DDDDE: & GDA-RRBPSG & GGDSGYEG & [YSLDAE] & EFSSDEDDGLYTREERAPRSGEDWKIRDERRPEVINGPNYG & PSRI & SNARE: \\
\hline aplan-Hungary & . & ... & & & $7 \ldots \ldots$ & & & & ... & .. \\
\hline NIA3-Japan & & & & & & & & & & \\
\hline Za-China-2001 & ... & R.A. & & ............ & VI......... & & ......?. & & & \\
\hline Min-A-China-2002 & & R.A. & & ......... & VI....... & & $\therefore \ldots$ & & . .. & xs.. \\
\hline Za-China-1999 & 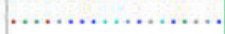 & R.A. & & ............ & . $I \ldots \ldots$. . . & & .2.... & & & \\
\hline HeN1-China-2012 & & R.A. & & ...... & . $\mathrm{II} \ldots . . . \mathrm{a}$ & & .A....?. & & ... & \\
\hline $\mathrm{NJ}-\mathrm{Ch}$ & , & R.A. & & ......... D. & 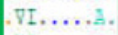 & & . A....?. & .. & . A.. & \\
\hline HuBBC-China-2016 & & R.A. & & ......... D. & VI........ & & .2...p. & & ... & Ys... \\
\hline HuBYC: & & R.A. & & & …..... & & $\therefore \ldots \mathrm{F}$ & & ... & Ms.. \\
\hline BubwX-Chin & & R.A. & & ..D. & ...... & & . A....?. & & .s.. & MS.. \\
\hline BuE & & R.A. & & ......... & . & & . A....?. & ...... $>2$ & .... & MS.. \\
\hline BuB & & R.A. & & .......... & ...... & & . a..... & & . . . & MS.. \\
\hline HuBH2 & & R.A. & & .. & ...... & & . $A \ldots$ P. & & .... & us.. \\
\hline HuBLL: & & RUA . & & & & & A....P. & & ... & MS... \\
\hline HuBQJ- & & R.A. & & .........D. & . $\nabla 1 \ldots . . .$. & & A...?. & & ... & Ms.. \\
\hline & & R.A. & & & .... & & ...... & & .... & MS.. \\
\hline HuBS: & & R.A. & & .D. & .... & & . A.... & &... & Ms.. \\
\hline bUt & & R.A. & & .D. & … & & A..... & &.$\times$. & MS... \\
\hline HeNz & .. & R.A. & & .. & ... & & . A....?. & & .... & MS.. \\
\hline BeNX: & & R.A. & & ....... D. & VI....... & & $.2 \ldots z$ & (n........... &.$s$. & MS.. \\
\hline HeNX & & R.A. & & & & & . & (2) & ... & .. \\
\hline China-2015 & & R.E. & & $-\ldots$ D. & … & & A....P. & & .s. & MS.. \\
\hline HeNPJC-China-2015 & $\cdots$ & R.A. & & & & & .....?. & 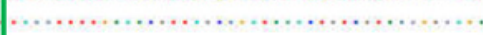 & .s.. & 8 \\
\hline GDHDY & & R.A. & $\cdots$ & & & & .à..... & & .s.. & s.. \\
\hline$G D-C h$ & & R.A. & & ........ & ..... & & . & & ... & Ms.. \\
\hline GDFC-China-2016 & & R.B. & & & & & A....?. & & ... & \\
\hline SDRz-China-2016 & & R.A. & & D......... & VI....... & & . & & . . . . & 4s.. \\
\hline $\mathrm{na} / 2016$ & & R.A. & & & $.7 \mathrm{I}$ & & . A..... E. & & .... & \\
\hline Huw-c & , & R.A. & $\because$ & ..-..... D. & …A. & & . A....?. & 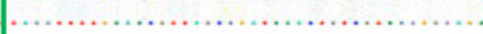 & rsa. & Ms.. \\
\hline $2 \mathrm{JHY}$ & ......... & R.A. & & 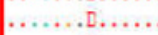 & VI........ & & A....P. & …………? & ... & MS.. \\
\hline $8 x-$ & & R.A. & & & & & .A...GP. & 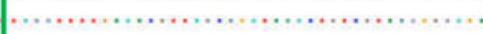 & .... & .. \\
\hline $\mathrm{JSBL}-\mathrm{Ch}$ & & B. & & & & & & & & \\
\hline
\end{tabular}




\section{Table 1 (on next page)}

Primers used in this study 
1 Table 1 Primers used in this study

\begin{tabular}{|c|c|c|c|}
\hline Primers & Sequences (5'-3') & Products (bp) & Effects \\
\hline gE1-F & CGTGTGGCTCTGCGTGCTGT & & Sample \\
\hline gE1-R & ATTCGTCACTTCCGGTTTC & 342 & detection \\
\hline gB2-F & GGCTGGTGGCGGTGTTTGGCG & 892 & Amplifying gB \\
\hline gB2-R & AGGGCGAAGGAGTCGTAGGG & 092 & Alitinging yo \\
\hline gC1-F & CCATGTGYGCCACTAGCATT & 965 & Amplifying the $\mathrm{N}$ - \\
\hline $\begin{array}{l}g C 1-R \\
g C 2-F\end{array}$ & CGGIGCIGT I GGICACGAAG & & Amplifying the C- \\
\hline $\mathrm{gC} 2-\mathrm{R}$ & GCCGTCGTCTCGTGTGGTT & 921 & terminal of $\mathrm{gC}$ \\
\hline gE2-F & GACCATGCGGCCCTTTCTGC & & Amplifying the $\mathrm{N}-$ \\
\hline gE2-R & GGTCCACCGGGCGCAGGCA & 899 & terminal of gE \\
\hline gE3-F & TTTACCGCCACGCTGGACTGGT & 1098 & Amplifying the C- \\
\hline
\end{tabular}

2

3

4

5

6

7

8

9

10

11

12

13 
Table 2 (on next page)

PRV reference strains used in this study 
1 Table 2 PRV reference strains used in this study

\begin{tabular}{|c|c|c|c|}
\hline Strain & $\begin{array}{c}\text { Year of } \\
\text { isolation }\end{array}$ & Place of isolation & GenBank accession \\
\hline Bartha & - & Hungary & JF797217.1 (complete genome) \\
\hline Becker & - & United States & JF797219.1 (complete genome) \\
\hline Kaplan & - & Hungary & JF797218.1 (complete genome) \\
\hline NIA3 & - & Japan & KU900059.1 (complete genome) \\
\hline $\mathrm{Fa}$ & 2001 & China & KM189913.1 (complete genome) \\
\hline TJ & 2012 & China/Tianjin & KJ789182.1 (complete genome) \\
\hline $\mathrm{BJ} / \mathrm{YT}$ & 2012 & China/Beijing & KC981239.1 (complete genome) \\
\hline ZJ01 & 2012 & China/Zhejiang & KM061380.1 (complete genome) \\
\hline HN1201 & 2012 & China/Henan & KP722022.1 (complete genome) \\
\hline HNX & 2012 & China/Henan & KM189912.1 (complete genome) \\
\hline HeN1 & 2012 & China/Henan & KP098534.1 (complete genome) \\
\hline HLJ8 & 2013 & China/Heilongjiang & KT824771.1 (complete genome) \\
\hline Ea & 1999 & China/Hubei & AF257079.1 (gB), AF158090.1 (gC), AF171937.1 (gE) \\
\hline GX-NL & 2007 & China/Guangxi & KT948044.1 (gB), KU323908.1 (gC), KT936469.1 (gE) \\
\hline GD-SH & 2007 & China/Guangdong & KT948054.1 (gB), KU323907.1 (gC), EF552427.1 (gE) \\
\hline GD-GZ & 2009 & China/Guangdong & KT948042.1 (gB), KU323905.1 (gC), KT936466.1 (gE) \\
\hline GD-GZ2 & 2013 & China/Guangdong & KT948045.1 (gB), KU323903.1 (gC), KT936467.1 (gE) \\
\hline $\mathrm{HN}-\mathrm{CZ}$ & 2013 & China/Hunan & KT948049.1 (gB), KU323912.1 (gC), KT936465.1 (gE) \\
\hline GD-FS & 2014 & China/Guangdong & KT948040.1 (gB), KU323909.1 (gC), KT936476.1 (gE) \\
\hline GD-HS2 & 2014 & China/Guangdong & KT948047.1 (gB), KU323911.1 (gC), KJ660063.1 (gE) \\
\hline GD-JM & 2015 & China/Guangdong & KT948048.1 (gB), KU323899.1 (gC), KT936473.1 (gE) \\
\hline GD-QY & 2010 & China/Guangdong & KT948053.1 (gB), KU323901.1 (gC) \\
\hline GX-GL & 2013 & China/Guangdong & KT948046.1 (gB), KU323910.1 (gC) \\
\hline GD-YF & 2015 & China/Guangdong & KT948041.1 (gB), KU323904.1 (gC) \\
\hline P-PrV & 2003 & Malaysia & EU915280.1 (gC), FJ176390.1 (gE) \\
\hline LXB6 & 2009 & China/Heilongjiang & GQ926931.1 (gC), GQ926932.1 (gE) \\
\hline SMX & 2014 & China/Henan & KR025920.1 (gC), KP192495.1 (gE) \\
\hline GD-WH & 2015 & China/Guangdong & KU323902.1(gC), KT936468.1(gE) \\
\hline HNXX & 2012 & China/Henan & KJ526436.1(gB), KJ526441.1(gC) \\
\hline HS & 2008 & China/Sichuan & EU719636.1(gC) \\
\hline Min-A & 2002 & China/Fujian & AY170318.1(gE) \\
\hline
\end{tabular}

2

3

4

5

6 


\section{Table 3 (on next page)}

Twenty-five strains of PRV isolated and analyzed in this study 
1 Table 3 Twenty-five strains of PRV isolated and analyzed in this study

\begin{tabular}{|c|c|c|c|c|}
\hline Strains & Place of isolation & Samples of isolation & Date of isolation & TCID50/0.1 mL \\
\hline HeNFJC & Henan & Lung & $2015 / 11$ & $10^{6.72}$ \\
\hline HeNJYG & Henan & Lung & $2015 / 11$ & $10^{7.38}$ \\
\hline GDFC & Guangdong & Lung & $2016 / 3$ & $10^{7.00}$ \\
\hline GD & Guangdong & Lung & $2016 / 3$ & $10^{7.25}$ \\
\hline HeNZZZM & Henan & Lung & $2016 / 3$ & $10^{7.25}$ \\
\hline HuBLLP & Hubei & Lung & $2016 / 3$ & $10^{7.59}$ \\
\hline FJFQ & Fujian & Lung & $2016 / 3$ & $10^{7.28}$ \\
\hline GDHDYC & Guangdong & Lung & $2016 / 3$ & $10^{7.49}$ \\
\hline $\mathrm{HuN}$ & Henan & Brain & $2016 / 3$ & $10^{7.96}$ \\
\hline SDRZ & Shandong & Lymph nodes & $2016 / 3$ & $10^{7.36}$ \\
\hline HuBYCYJ & Hubei & Lymph nodes & $2016 / 4$ & $10^{7.67}$ \\
\hline HeNXY & Henan & Lung & $2016 / 4$ & $10^{7.08}$ \\
\hline HuBWX & Hubei & Lung & $2016 / 4$ & $10^{7.25}$ \\
\hline SDSCL & Shandong & Lung & $2016 / 5$ & $10^{7.80}$ \\
\hline $\mathrm{HuBHC}$ & Hubei & Lung & $2016 / 5$ & $10^{7.59}$ \\
\hline HuBAL & Hubei & Brain & $2016 / 9$ & $10^{7.12}$ \\
\hline HuBZX & Hubei & Brain & $2016 / 9$ & $10^{7.40}$ \\
\hline ZJHY & Zhejiang & Lung & $2016 / 10$ & $10^{7.25}$ \\
\hline$S X$ & Shanxi & Lung & $2016 / 10$ & $10^{7.57}$ \\
\hline HeNXP & Henan & Brain & $2016 / 11$ & $10^{7.25}$ \\
\hline $\mathrm{HuBHZ}$ & Hubei & Lung & $2016 / 11$ & $10^{7.12}$ \\
\hline HuBQJ & Hubei & Lung & $2016 / 11$ & $10^{7.00}$ \\
\hline HuB & Hubei & $\underline{\text { Tonsil }}$ & $2016 / 12$ & $10^{7.35}$ \\
\hline JSZL & Jiangsu & Brain & $2016 / 12$ & $10^{7.43}$ \\
\hline HuBSP & Hubei & Brain & $2016 / 12$ & $10^{7.54}$ \\
\hline
\end{tabular}

2 